\title{
The Effect of Delamination on Damage Path and Failure Load Prediction for Notched Composite Laminates
}

\author{
Arunkumar Satyanarayana* \\ Swales Aerospace \\ Hampton, VA 23681 \\ Philip B. Bogert ${ }^{\dagger}$ \\ NASA Langley Research Center \\ Hampton, VA 23681 \\ Prasad B. Chunchu \\ Eagle Aeronautics \\ Hampton, VA 23669
}

\begin{abstract}
The influence of delamination on the progressing damage path and initial failure load in composite laminates is investigated. Results are presented from a numerical and an experimental study of center-notched tensile-loaded coupons. The numerical study includes two approaches. The first approach considers only intralaminar (fiber breakage and matrix cracking) damage modes in calculating the progression of the damage path. In the second approach, the model is extended to consider the effect of interlaminar (delamination) damage modes in addition to the intralaminar damage modes. The intralaminar damage is modeled using progressive damage analysis (PDA) methodology implemented with the VUMAT subroutine in the ABAQUS finite element code. The interlaminar damage mode has been simulated using cohesive elements in ABAQUS. In the experimental study, 2-3 specimens each of two different stacking sequences of center-notched laminates are tensile loaded. The numerical results from the two different modeling approaches are compared with each other and the experimentally observed results for both laminate types. The comparisons reveal that the second modeling approach, where the delamination damage mode is included together with the intralaminar damage modes, better simulates the experimentally observed damage modes and damage paths, which were characterized by splitting failures perpendicular to the notch tips in one or more layers. Additionally, the inclusion of the delamination mode resulted in a better prediction of the loads at which the failure took place, which were higher than those predicted by the first modeling approach which did not include delaminations.
\end{abstract}

\section{Introduction}

As the motivation increases to use composite materials in aerospace structures, researchers are investigating the sensitivity of these materials to damage. There are a number of sources of airframe initial damage. Two that have received considerable attention are delaminations and notches. A delamination can occur during manufacturing or from an impact on the structure. Also, delaminations can occur due to interlaminar stresses [1]. These stresses are generated due to mismatches in Poisson's ratio and in-plane stress gradients. A through notch can result from a forklift or a rotorburst puncture of a fuselage, for example. Designers want to know whether damage will propagate under loading in order to assess continued airworthiness. Propagating damage can be intralaminar in nature (fiber breakage or matrix cracking within a layer of the laminate) or interlaminar in nature (delamination or disbonding of adjacent layers of the laminate). In many cases, the accumulation of damage involves both the intra and interlaminar modes. In such cases it is important to consider both damage modes in a progressive damage analysis (PDA) of the structure in order to accurately predict the damage path and failure load.

\footnotetext{
* Senior Research Engineer,

Aerospace Engineer, Structural Mechanics and Concepts Branch.

* Senior Research Engineer, Member AIAA.
} 
There have been numerous studies considering the effects of interlaminar damage in composites. Some researchers in the past have shown that stacking sequence has an influence on the initiation of delaminations [2-5]. Other researchers have studied and concluded that delaminations can have a significant effect on a laminate's compressive strength. Progressive delamination analysis has been performed in Reference [6], to predict delamination growth between a composite skin and a stiffener using the Virtual Crack Closure Technique (VCCT) implemented within ABAQUS. In References [7-8] interface elements were used to model inter-laminar damage initiation and its progression, whereas in Reference [9], inter-laminar damage was modeled using a fracture energy based criterion for initiation and propagation of damage between two lamina. The authors in Reference [10] have utilized a cohesive element in the ABAQUS finite element code to predict the delamination response in a notched tensile-loaded laminated coupon. Intralaminar damage was not considered and no comparison with experimentally observed failure loads was mentioned. There have also been numerous studies considering the effects of intralaminar damage in composites. Intralaminar failure modes have been modeled in References [9, 11-14] using Hashin's failure criteria [15]. Hashin's failure criteria have been modified to account for tensile fiber failure due to transverse shear loading in References [16]. Qing, Chang and Starnes [17] used an intralaminar progressive failure algorithm in conjunction with ABAQUS to predict the damage patterns and tensile failure loads of notched laminates with co-cured reinforcing strips. Analytical failure loads agreed well with test data for a variety of notch sizes and reinforcing strip thicknesses when the damage mode was dominated by self-similar crack progression. When thicker reinforcing strips were used, splitting accompanied by delamination of the strip occurred when the damage reached the strip. This led to a $12 \%$ over-prediction in failure load. In the authors' previous research [18] it was observed that a modeling approach that included only the intralaminar damage modes, underpredicted the failure load by $20 \%$ in an un-stiffened notched tension loaded laminate, where significant delamination was observed experimentally. These results support the inclusion of interlaminar effects in future code development. There have not been many studies where both intra and interlaminar damage modes are considered together. The modeling in Reference [7] considers the interaction between intralaminar matrix cracking and delamination by providing an empirical coupling relationship between matrix cracking and delamination.

A majority of the progressive damage analyses have considered either interlaminar failure alone or intralaminar failures only and have not accounted for the interaction between the two, resulting in considerable discrepancies between the predicted and experimental results. Motivated by the need to more accurately predict the damage modes, and the damage progression in laminated structures, in the current work a PDA approach has been implemented that extends our previous work [18] by including both intralaminar and interlaminar damage modes in the prediction of damage progression. The methodology should be applicable to general damaged or undamaged laminated structures. The focus in this paper will be the application of the methodology to tensile loaded notched laminated coupons.

In this paper, results are presented from a numerical and experimental study of center-notched tensile loaded specimens. The numerical study includes two approaches. In the first approach, the author's previous PDA approach is utilized. It only considers intralaminar damage modes in calculating the progression of the damage path. Damage initiation and post initiation degradation of the properties of the failed elements associated with intralaminar failure modes have been implemented through the VUMAT subroutine in the ABAQUS finite element code. In the second approach, the effect of the interlaminar damage mode in addition to the intralaminar modes are considered in calculating the progression of the damage path. The interlaminar damage mode (delamination) predictions have been incorporated by using COHESIVE elements within ABAQUS. The numerical models represented the specimens used in the experimental study which consisted of 2-3 specimens each of two different laminates. Both laminates types consist of 10 plys with the same percentages of $0^{\circ}, 45^{\circ}$ and $90^{\circ}$ plies but had different stacking sequences. The numerical results from the two different modeling approaches, which include load-end displacement, notch tip strains, and individual ply damage modes, are compared with each other and the experimentally observed results for both laminate types. In the second modeling approach, where delaminations are considered, the calculated delaminations are compared with those observed experimentally for both laminate types. An assessment of the comparisons reveals that the second modeling approach, where delamination damage modes are included, better matches the experimentally observed damage paths, which were predominantly splitting perpendicular to the notch tips in a number of layers, and the loads at which the splitting took place, which were higher than those predicted by the first modeling approach which did not include delaminations.

\section{Progressive Damage Analysis}

An analysis methodology for predicting damage initiation and propagation, and failure of laminated composite panels with a center notch is developed using a progressive damage analysis methodology implemented within the ABAQUS/explicit finite element analysis code. The use of an explicit analysis code for simulating the 
progressive damage of statically loaded specimens is documented in the author's previous work [18] but has much to do with the desire to predict fast running cracks in the future. The progressive damage analysis methodology includes intralaminar and interlaminar damage initiation and progression. Both geometric and material nonlinearities are included in the analysis. Material nonlinear behavior is associated with degradation of the material properties of the plies and degradation of the material in-between the plies to simulate the intralaminar and interlaminar damage mechanisms, respectively. Details of the methods used to simulate the intralaminar and interlaminar damage progression are presented in the next two subsections.

\section{A. Intralaminar Damage}

The intralaminar damage modes considered in the current study are:

a. Fiber failure in tension and compression, and

b. matrix failure in tension, compression and shear.

The Hashin-Rotem unidirectional criteria [16] are used in the present study to predict intralaminar damage initiation. The ply stresses in the principal material directions are used in the unidirectional failure criteria. The failure criteria are expressed in terms of the in-plane stresses $\sigma_{i j}$, and the strengths $X$, and $Y$ and the shear allowable $S$. The in-plane stresses are $\sigma_{11}, \sigma_{22}$, and $\sigma_{12}$, where direction 1 is the fiber direction and direction 2 is the transverse direction in the ply. The strengths parallel and transverse to the fiber direction are denoted as $X$ and $Y$, respectively, and the in-plane shear strength is $S_{12}$. The subscripts 'c' and ' $t$ ' denote compression and tension, respectively. In the current study, insitu strengths were used for $Y_{t}, Y_{c}$ and $S_{12}[19]$.

The fiber-failure index, $e_{\mathrm{f}}$, in tension and in compression is defined as

$$
\begin{aligned}
& e_{f}^{2}=\left(\frac{\sigma_{11}}{X_{t}}\right) \text { for } \sigma_{11}>0 \\
& e_{f}^{2}=\left(\frac{\sigma_{11}}{X_{c}}\right) \text { for } \sigma_{11}<0
\end{aligned}
$$

The failure index, $e_{\mathrm{m}}$, for matrix cracking in tension, compression and shear is defined as,

$$
\begin{array}{ll}
e_{m}^{2}=\left(\frac{\sigma_{22}}{Y_{t}}\right)^{2}+\left(\frac{\sigma_{12}}{S_{12}}\right)^{2}, & \sigma_{22}>0 \\
e_{m}^{2}=\left(\frac{\sigma_{22}}{Y_{c}}\right)^{2}+\left(\frac{\sigma_{12}}{S_{12}}\right)^{2}, & \sigma_{22}<0
\end{array}
$$

The progressive damage analysis in ABAQUS/Explicit is implemented using a user-written subroutine VUMAT [20]. The VUMAT subroutine is invoked at each material point of an element to evaluate the failure criteria. When damage initiation is predicted at the material point, stresses are set to zero according to the degradation model presented in Table 1 to represent the degradation of the material associated with different damage modes. When the fiber failure criteria is satisfied, or, when any of the transverse or shear strains reach 0.5 at the material point, then that material point in the element is flagged for deletion. Once a material point has been deleted, it cannot be reactivated. The ABAQUS/Explicit code checks for elements where all of the material points have been flagged as deleted and removes these elements from further computations.

\section{B. Interlaminar Damage (Delamination)}

Interlaminar damage is simulated using the ABAQUS cohesive finite element COH3D8 at the ply interfaces. The interlaminar damage model is based on a continuum-damage-mechanics formulation of a stress-strain constitutive law for a thin resin layer that exists between adjacent composite lamina. The on-set of delamination is determined based on an interlaminar maximum stress obtained from a multi-axial stress criterion and the delamination growth is based on a critical fracture energy criterion. Damage is modeled as irreversible by including a damage parameter. The damage parameter is directly related to the dissipated fracture energy. The guidelines presented in Reference [21] have been used in the current study to calculate cohesive layer parameters such as mesh size, stiffnesses and the interfacial strengths of the interface (cohesive layer) between the plies. The equation presented in Reference [21] to define the stiffness of the cohesive layer in the mode-I direction is: 


$$
K_{I} \approx\left(\frac{\alpha E_{3}}{t}\right)
$$

Where $E_{3}$ is the Young's modulus of the laminate in the thickness direction, $t$ is the larger of the sublaminate thicknesses above or below the cohesive layer and $\alpha$ is a parameter that is much larger than 1 . The authors in Reference [21] recommend the use of a value equal to or greater than 50 for $\alpha$ to obtain a stiffness of the cohesive layer which is small enough to avoid numerical problems such as spurious oscillations of the tractions in an element and also large enough to prevent the laminate from being too compliant in the thickness direction. Hence in this study a value of 50 has been considered. In calculating the stiffness, $K_{I I}$ and $K_{I I I}$ in the shear directions (mode-II and mode-III directions), $E_{3}$ is replaced by the shear moduli $\mathrm{G}_{12}$ and $\mathrm{G}_{13}$ of the laminate respectively.

Interfacial strengths, required to simulate delamination, are determined based on the in-plane mesh size of the cohesive layer, the fracture toughness of the material and the number of elements in the cohesive zone using the following equation for mode-I failure:

$U_{I}=\sqrt{\frac{9 \pi E_{3} G_{I}}{32 N_{e} l_{e}}}$

where $U_{I}$ is the interlaminar strength in the mode-I direction, $G_{I}$ is the corresponding fracture toughness, $N_{e}$ is the desired number of elements in the cohesive zone and $l_{e}$ is the length of the finite element in the cohesive layer [21]. The other interfacial strengths, $U_{I I}$ and $U_{I I I}$ are computed in the mode-II and mode-III directions by replacing $G_{I}$ in the above equation with the $G_{I I}$ and $G_{I I I}$ respectively.

\section{Experimental Description}

Two laminate stacking sequences, shown in Table 3 were considered in the progressive damage analysis study. Both laminates had the same percentages of $0^{\circ}, 45^{\circ}$ and $90^{\circ}$ degree plies, but the stacking sequence was varied to study the evolution of delamination at different interfaces. The geometric description of the center-notched laminate specimens is shown in Figure 1. The specimens have a test section of 6 inches $x 3$ inches. The specimens have a 2.75 inch long tab section on each end, which fits into the grips of a servo-hydraulic testing machine and the specimens have a notch dimension of 0.75 inches x 0.09375 inches.

Four axial strain gauges were mounted on the specimens to measure strain data during the loading. The strain gage locations on the specimens are shown in Figure 2. EA-06-070LC-350 type strain gages were mounted on the notch tips. CEA-06-187UW-350 type gages were mounted at the other locations. Two extensometers of 4 inches span length were installed on the two vertical longitudinal edges of the specimens, with the ends equidistant from the horizontal notch line to provide a direct measurement of the elongation throughout the loading. Figure 3 shows one of the specimens mounted in the test machine. The specimens were statically loaded in tension at room temperature, under displacement control at a rate of 0.005 inches/minute, and the test data were acquired every half second.

The specimens are fabricated from T800/3900-2 pre-preg tape, a toughened epoxy CFRP composite material. Stiffness properties and strength allowables are given in Table 2. The laminate sequences and their corresponding thicknesses are defined in Table 3. Three specimens of laminate-1 and two specimens of laminate- 2 were loaded above the initial failure load but lower than the ultimate failure load of the specimens. The observed initial failure load was splitting of some of the plies at the notch tips, with splits propagating perpendicular to the notch direction all the way to the grips. The intralaminar splitting was accompanied by delaminations. The ultimate failure load, characterized by the separation of the specimen into two or more pieces, occurred at a load a few thousand pounds higher. Only one specimen of laminate- 2 was loaded to ultimate failure, at which point, post test investigation of the specimen was meaningless.

\section{Finite Element Model Description}

Two finite element models, one a 2-D model and the other a 3-D model were developed to perform the PDA using the ABAQUS/Explicit code. The 2-D, 4-node shell model, used in the predictions of intralaminar damage modes only, is shown in Figure 4. The finite element model includes only the test section, which is of 3.0 inches wide and 6.0 inches long with a center notch of 0.75 inches x 0.09375 inches. The 2-D finite element model of the specimen is discretized using 4-node quadrilateral elements whose size is approximately 0.08 inches x 0.08 
inches. The finite element type used in the intralaminar progressive failure analyses is the ABAQUS S4R and the model consists of 3012 nodes and 2888 elements for each laminate sequence.

A 3-D model was developed to simulate coupled inter- and intralaminar damage modes. The thickness of this model is divided in to 5 sections with a cohesive layer between each of the sections. The pictorial representation of the thickness discretization of both of the laminates is shown in Figure 5. In case of laminate-1, the $1^{\text {st }}$ and $5^{\text {th }}$ sections consist of $\left[45^{\circ}\right]$ plies, the $2^{\text {nd }}$ and $4^{\text {th }}$ sections consist of $\left[0^{\circ} /-45^{\circ} / 0^{\circ}\right]$ plies and the $3^{\text {rd }}$ section consists of $\left[90^{\circ} / 90^{\circ}\right]$ plies. The cohesive layers were included at the $0^{\circ} / 90^{\circ}$ and the $0^{\circ} / 45^{\circ}$ interfaces where delamination is most likely to occur due to Poision's ratio mismatch and the coefficient of mutual influence of the adjacent plies respectively. In the case of laminate- 2 , the $1^{\text {st }}$ and $5^{\text {th }}$ sections consist of $\left[0^{\circ} / 0^{\circ}\right]$ plies, the $2^{\text {nd }}$ and $4^{\text {th }}$ sections consist of $\left[45^{\circ}\right]$ plies and the $3^{\text {rd }}$ section consists of $\left[-45^{\circ} / 90^{\circ} / 90^{\circ} /-45^{\circ}\right]$ plies. The cohesive layers were modeled between $0^{\circ}$ and $45^{\circ}$ plies and also between $45^{\circ}$ and $-45^{\circ}$ plies, interfaces which were unique to laminate- 2 . The stacking sequences for the laminates including the cohesive layers are presented in Table 4. Each section of the 3-D model is discretized using one ABAQUS SC8R (8-node shell continuum) element in the thickness direction. The assemblage of the five sections and four cohesive layers through the thickness defines the laminates. SC8R elements of size 0.08 inches x 0.08 inches, were adopted to discretize the in-plane direction. The cohesive layers were modeled using a zero thickness ABAQUS 8-node cohesive element known as COH3D8. An in-plane discretization of 0.02 inches $\times 0.02$ inches, was maintained in the cohesive layers which require a finer mesh. The interfacial boundaries between the sub-laminate and the cohesive layers were connected using "Tie" boundary conditions to accommodate the different mesh sizes.

In the 2-D model, one of the transverse (horizontal) edges is fixed in all the translational and rotational degrees of freedom about the $\mathrm{x}, \mathrm{y}$ and $\mathrm{z}$ directions. The other transverse edge is fixed in the $\mathrm{y}$ and $\mathrm{z}$ translational and $\mathrm{x}, \mathrm{y}$ and $\mathrm{z}$ rotational degrees of freedom but a uniform end-displacement was applied in the $\mathrm{x}$ direction. In case of the 3-D model, one of the transverse (horizontal) edges is fixed in all the translational degrees of freedom ( $\mathrm{x}, \mathrm{y}$ and $\mathrm{z}$ directions). The other transverse edge is fixed in the $y$ and $\mathrm{z}$ translational degree of freedom but a uniform enddisplacement was applied in the $\mathrm{x}$ direction. In both the 2-D and 3-D models, the two long (vertical) edges are left free.

The 3-D model requires interfacial properties of the cohesive layer to simulate delaminations. Hence, the properties such as interlaminar stiffnesses and strengths are evaluated using equations 3 and 4 . In equation 3 the thickness $t$ was determined based on the maximum number of plies between any cohesive layers. Hence the values of $t$ equal to 3 ply thicknesses and 4 ply thicknesses were considered for laminate- 1 and laminate-2 respectively, to calculate interfacial stiffnesses. The interfacial strengths were calculated by adopting two finite elements in the cohesive zone [21] with the length of the element being 0.02 inches. The interlaminar strengths and stiffnesses values are presented in Table 5 for both laminate- 1 and laminate- 2 .

The progressive damage analysis was performed by applying a uniform end displacement of 0.05 inches and 0.06 inches along the $0^{\circ}$ (fiber) direction for the 2-D and 3-D models respectively, over a period of 0.01 seconds. The end displacement was applied in a ramp fashion and a mass density of $0.000154 \mathrm{lbs}-\mathrm{sec}^{2} / \mathrm{in}^{4}$ for the composite material was used in the analysis. During the entire simulation, the kinetic energy of the model was checked to ascertain that it did not exceed $10 \%$ of the total strain energy of the model in accordance with the ABAQUS user's manual guidelines for simulating static problems using the explicit finite element code [20]. This was necessary to ensure that while simulating a pseudo-static analysis, significant dynamic effects were not introduced while using the fictitiously small total loading time required for computational efficiency in an explicit analysis.

\section{Results and Discussion}

Results including the load-end displacement curve and the notch-tip strain, obtained from both the experiment and the 2-D and 3-D progressive damage analyses are presented. C-scan pictures of the damaged specimens and the simulated interlaminar and intralaminar damage paths are also presented in Figures 6-17. The axial stress distribution, before and after delamination initiation in the $0^{\circ}$ ply, obtained from the 3-D PDA is presented for laminate-2.

\section{A. Laminate-1}

Three specimens of this laminate sequence were loaded to 15,300.0 lbs in tension. In Figure 6, the loadend displacement curve obtained from the experiment, and the curves predicted from the 2-D and 3-D PDA have been presented. In this figure, it can be seen that the 2-D PDA predicts complete failure of the specimen at 13,613.0 lbs which is represented by the red curve in the figure, indicating the loss of load carrying capability of the specimen. In contrast, the curve predicted from the 3-D PDA, shown in green, indicates a small change in the slope 
at 13,330.0 lbs., but shows that the laminate continued to carry load, which is more consistent with the experiment, shown in blue. Also, at 13,300.0lbs, it was observed that the 3-D PDA predicts matrix damage and delaminations around the notch tip, and fiber damage in the $-45^{\circ}$ plies. At 15,316.0 lbs the simulation was stopped as was the case with the experiment. The load vs. end displacement prediction from 3-D PDA and the experimental data agree reasonably well up to the maximum applied load. In Figure 7, the strain predictions from 2-D and 3-D PDA, and the measured strain at the notch-tip are presented. It can be observed in this figure that the measured strain remains linear only within a short load range and then becomes nonlinear as the specimen is loaded further. The high strain value, which is in excess of $3 \%$, is well above the fiber failure strain. This implies that this is a surface phenomenon at the notch-tips and needs additional study.

In Figure 8, the damage mode predictions from the 2-D PDA are presented. In this figure all of the plies except the $90^{\circ}$ ply in the laminate failed in the fiber damage mode. However the 90 degree plies failed in the matrix damage mode. Hence, it is obvious from these pictures that the 2-D PDA predicts a through crack, initiating at the notch tips with propagation in a self-similar fashion all the way to the free edge when all of the damage modes are integrated through the thickness. The red and blue colors in the picture indicate the damaged and the undamaged areas in the plies respectively. In Figure 9 the intralaminar damage predictions from the 3-D PDA are presented. The dominant damage mode in all of the plies except the $-45^{\circ}$ plies is in the matrix damage mode with splitting occurring perpendicular to the notch tip. The $-45^{\circ}$ plies in the laminate failed in the fiber damage mode which in turn caused a noticeable change in the stiffness of the laminate, which also can be observed in Figure 6. However the load carrying plies $\left(0^{\circ}\right.$ plies $)$ did not show fiber damage when the simulation was stopped indicating additional unused load carrying capacity. In Figure 10 the interlaminar damage (delamination) predictions at the $45^{\circ} / 0^{\circ}$ interface and the $0^{\circ} / 90^{\circ}$ interface are presented. The red and blue/green colors in the picture indicate complete delamination and no delamination respectively. Comparing the simulated delamination with the one recorded by the $\mathrm{C}$-scan in Figure 11, it is clear that there is a good qualitative agreement between them. Also in Figure 11b, the popping of the 45 degree ply starting from the notch-tip, splitting in a "Z" fashion due to delamination at the $45 / 0$ interfaces is presented.

\section{B. Laminate-2}

Three specimens of this laminate sequence were loaded in tension. Two specimens were loaded to $21,280.0 \mathrm{lbs}$ and the other one was loaded to $23,820.0 \mathrm{lbs}$ which caused the specimen to fail completely. The experimental results presented in Figures 12-17 correspond to the specimens which were loaded to 21,280.0 lbs. In Figure 12 the load-end displacement curves obtained from the experiment, 2-D and 3-D PDAs are presented. The curve predicted by the 2-D PDA indicates a complete self-similar failure at 13,618.0 lbs. However, the curve predicted by the 3-D PDA indicates a small change in the slope from the measured load-end displacement curve and further load carrying capacity to $14,387.0 \mathrm{lbs}$. Unfortunately, at this load level the analysis terminated due to an excessive distortion in one of the elements. Therefore it was not possible to see the additional load carrying capacity observed in the experiment. In Figure 13, the axial strain predictions at the notch-tip from the 2-D and 3-D PDA's and the experimental results are presented. The important observation is that the strain values predicted by the 3-D PDA are matching very well with the experimental data, which was not the case for laminate-1. And moreover, as laminate-2 has $0^{\circ}$ outer plies, the nonlinearity in the measured load-strain curve at the notch-tip is significantly reduced as compared to the one shown for laminate-1, which has $45^{\circ}$ outer plies. From this observation, the authors feel that the non-linearity of the strain at the notch-tips observed in laminate-1 is a local phenomenon. In Figure 14, the axial stress distribution in one of the $0^{\circ}$ plies (load carrying plies) before and after the delamination at the $0^{\circ} / 45^{\circ}$ interface is presented. It can be clearly noticed from this figure that the delamination decreases the notch-tips stress and hence increases the load carrying capability of the specimen by redistributing load in the load carrying $0^{\circ}$ plies.

In Figure 15, the damage mode prediction from 2-D PDA is presented. In this figure all of the plies except the $90^{\circ}$ ply in the laminate failed in the fiber damage mode again in a self-similar manner. However the $90^{\circ}$ plies failed in the matrix damage mode. In Figure 16, only the matrix damage predictions from the 3-D PDA are presented as there was no fiber damage present in any of the plies. In Figures 17 and 18 the delaminations predicted at the $0^{\circ} / 45^{\circ}$ and $45^{\circ} /-45^{\circ}$ interfaces from the 3-D PDA and the delamination observed experimentally from the CScan are presented. It can be observed that the predicted delamination shape is in reasonable agreement with the measured one. However, hardly any delamination was predicted at the $45^{\circ} /-45^{\circ}$ interface.

\section{Conclusions}

The influence of delamination in altering the damage modes, the damage path and the initial failure load of notched composite specimens has been successfully demonstrated. It is evident that a 2-D PDA with intralaminar failures only, predicts complete failure of the specimen at a lower load and with self similar cracks emanating from 
the notch tips for laminate-1 and laminate-2. The interlaminar damage mode (delamination) has been predicted for two tensile loaded notched laminate sequences using the 3-D PDA. From the 3-D PDA, delaminations were predicted between plies, which in turn increased the load carrying capacity of the specimen which is evident in Figures 6 and 12. The authors' believe that the predicted and experimentally observed increase in load carrying capacity is due to load redistribution around the notch tips, shown in Figure 14, caused by energy dissipation during the delamination process. The intralaminar damage mode and damage path predictions from the 2-D and 3-D PDA were also different in most of the plies for both the laminates. Hence, these results suggest that the delamination alters the damage modes at the notch-tips considerably and without modeling delamination, one would arrive at the wrong damage modes and ultimately the wrong initial failure load for laminates prone to delamination.

\section{References}

1. Lorriott, Th., Marion, G., Harry, R., and Wargnier, H., "Onset of free-edge delamination in Composite Laminates Under Tensile Loading,"Composites Part B: Engineering, Vol. 34, 2003, pp. 459-471.

2. Garg, C. A., "Delamination-A Damage Mode in Composite Structures," Engineering Fracture Mechanics, Vol 29, No. 5, pp. 557-584, 1988.

3. Tan, C. S., "Stress Concentrations in Laminated Composites," Technomic Publishing Company, Inc., 851 New Holland Avenue, Box 3535, Lancaster, Pennsylvania 17604.

4. Tao, J., and Sun, C. T., "Influence of Ply Orientation on Delamination in Composite Laminates," Journal of Composite Materials, Vol. 32, No.21, 1998, pp. 1933-1947.

5. Hallett, S. R., and Wisnom, M. R., "Experimental Investigation of Progressive Damage and the Effect of Layup in Notched Tensile Tests," Journal of Composite Materials, Vol. 40, January, 2006, pp. 119-141.

6. Bisagni, C., "Progressive Delamination Analysis of Stiffened Composite Panel in Post-Buckling", Proceedings of the AIAA/ASME/ASCE/AHS/ASC $47^{\text {th }}$ Structures, Structural Dynamics \& Materials Conference, AIAA paper No. 2006-2178, 2006.

7. Borg, R., Nilsson, L., Simonsson, K., "Simulation of Low Velocity Impact on Fiber Laminates Using a Cohesive Zone Based Delamination Model," Composites Science and Technology, Vol. 64, 2004, pp. 279-288.

8. Guinard, S., Allix, O., Guedra-Degeorges, D., Vinet. A., "A 3D Damage Analysis of Low-Velocity Impacts on Laminated Composites," Composites Science and Technology, Vol. 62, 2002, pp. 585-589.

9. Gama, B. A., Xiao, J. R., Hague, M. J., Yen, C. F., and Gillespie, J. W., Jr., "Experimental and Numerical Investigations on Damage and Delamination in Thick Plain Weave S-2 Glass Composites Under Quasi-Static Punch Shear Loading," $18^{\text {th }}$ Annual Technical Conference of American Society for Composites, University of Florida, Gainesville, FL, October 19-22, 2003.

10. Yang, Q., and Cox, B., "Cohesive models for damage evolution in laminated composites", International Journal of Fracture, 2005, pp. 107-137, DOI 10.1007/s10704-005-4729-6.

11. Davies, G. A. O., and Zhang, X., "Impact Damage Prediction in Carbon Composite Structures," International Journal of Impact Engineering, Vol. 16, No. 1, 1995, pp. 149-170.

12. Yen, C. F., and Cassin, T., "Progressive Failure Analysis of Thin Walled Composite Tubes under Low Energy Impact," Proceedings of the AIAA/ASME/ASCE/AHS/ASC $39^{\text {th }}$ Structures, Structural Dynamics \& Materials Conference, AIAA paper No. 98-1742, pp. 363-371, 1998.

13. Minnetyan, L., and Abdi, F., "Dynamic Impact Loading Damage Propagation in Composite Structures," Proceedings of the AIAA/ASME/ASCE/AHS/ASC $45^{\text {th }}$ Structures, Structural Dynamics \& Materials Conference, AIAA paper No. 2004-1688, 2004.

14. Yen, C.F., "Analysis of Impact Damage Progression in Composite Structures," Proceedings of the $5^{\text {th }}$ LSDYNA User Conference, Southfield, Michigan, USA, September 21-22, 1998.

15. Hasin, Z., "Failure Criteria for Unidirectional Fiber Composites," Journal of Applied Mechanics, Vol. 47, 1980, pp. 329-334.

16. Hashin, Z., and Rotem, A., "A Fatigue Failure Criterion for Fiber Reinforced Composite Materials”, Journal of Composite Materials, Vol. 7, October 1973, pp. 448-464.

17. Qing, X, Chang, F.K., Starnes, J., "Damage Tolerance of Notched Composite Laminates with Reinforcing Strips," Journal of Composite Materials, Vol. 37, No. 02/2003.

18. Bogert, B. P., Satyanarayana, A., Chunchu, B. P., "Comparison of Damage Path Predictions for Composite Laminates by Explicit and Standard Finite Element Analysis Tools," Proceedings of the AIAA/ASME/ASCE/AHS/ASC $47^{\text {th }}$ Structures, Structural Dynamics \& Materials Conference, AIAA paper No. 2006-1650, 2006. 
19. Camanho, P.P., Dávila, C.G., Pinho, S.T., Iannucci, L., and Robinson, P., "Prediction of in-Situ Strengths and Matrix Cracking in Composites under Transverse Tension and in-Plane Shear," Composites Part A: Applied Science and Manufacturing, 2005.

20. ABAQUS User's Manual, Vol. 1-3, Version 6.4, Hibbitt, Karlsson, and Sorensen, Pawtucket, RI, 2003.

21. Turon, A., Davila, C. G., Camanho, P. P., Costa, J., "An engineering solution for mesh size effects in the simulation of delamination using cohesive zone models", Engineering Fracture Mechanics (2006), doi:10.1016/j.engfracmech.2006.08.025. 
Table 1. Degradation model for ABAQUS/Explicit VUMAT.

\begin{tabular}{ll}
\hline \hline Damage mode & Stresses set to zero \\
\hline Fiber failure in tension and compression & All stresses \\
Matrix cracking in tension, compression and shear & $\sigma_{22,} \sigma_{12}$ \\
\hline \hline
\end{tabular}

Table 2. Material properties and strength data.

\begin{tabular}{lll}
\hline \hline Properties & $\begin{array}{c}\text { T800/3900-2 } \\
(\mathbf{X ~ 1 0} \mathbf{~ p s i ) ~}\end{array}$ & \multicolumn{1}{c}{ Description } \\
\hline $\mathrm{E}_{11}$ & 23.2 & Young's modulus in fiber direction \\
$\mathrm{E}_{22}$ & 1.3 & Young modulus in the transverse direction \\
$\mathrm{G}_{12}$ & 0.9 & In-plane shear modulus \\
$\mathrm{X}_{\mathrm{t}}$ & 0.412 & Tensile strength in the fiber direction \\
$\mathrm{X}_{\mathrm{c}}$ & 0.225 & Compressive strength in the fiber direction \\
$\mathrm{Y}_{\mathrm{t}}$ & 0.00872 & Tensile strength in the transverse direction \\
$\mathrm{Y}_{\mathrm{c}}$ & 0.0243 & Compressive strength in the transverse direction \\
$\mathrm{S}_{12}$ & 0.01376 & In-plane shear strength \\
$\mathrm{v}_{12}$ & 0.28 & Poission's Ratio \\
$G_{I}$ & 0.86 in-lbs/in & Energy release rate in mode I \\
$G_{I I}, G_{I I I}$ & 2.7 in-lbs/in & Energy release rate in mode II and mode III \\
\hline \hline
\end{tabular}

Table 3. Specimen Specifications of 4-Node shell model.

\begin{tabular}{cccc}
\hline \hline ID & $\begin{array}{c}\text { Ply Percentages } \\
\text { [0's/45's/90's] }\end{array}$ & Laminate Stacking Sequence & $\begin{array}{c}\text { Thickness } \\
\text { (inches) }\end{array}$ \\
\hline Laminate -1 & {$[40 \% / 40 \% / 20 \%]$} & {$[45 / 0 /-45 / 0 / 90]_{\mathrm{s}}$} & 0.065 \\
Laminate -2 & {$[40 \% / 40 \% / 20 \%]$} & {$\left[0_{2} / 45 /-45 / 90\right]_{\mathrm{s}}$} & 0.065 \\
\hline \hline
\end{tabular}

Table 4. Specimen Specifications of 8-Node shell model.

\begin{tabular}{cccc}
\hline \hline ID & $\begin{array}{c}\text { Ply Percentages } \\
\text { [0's/45's/90's] }\end{array}$ & Laminate Stacking Sequence & $\begin{array}{c}\text { Thickness } \\
\text { (inches) }\end{array}$ \\
\hline Laminate -1 & {$[40 \% / 40 \% / 20 \%]$} & {$[45 / \mathrm{decoh} / 0 /-45 / 0 / \mathrm{decoh} / 90]_{\mathrm{s}}$} & 0.065 \\
Laminate -2 & {$[40 \% / 40 \% / 20 \%]$} & {$\left[0_{2} / \mathrm{decoh} / 45 / \mathrm{decoh} /-45 / 90\right]_{\mathrm{s}}$} & 0.065 \\
\hline \hline
\end{tabular}

Table 5. Cohesive Layer Parameters.

\begin{tabular}{lll}
\hline \hline \multicolumn{1}{c}{ Parameters } & \multicolumn{1}{c}{ Cohesive layer } & \multicolumn{1}{c}{ Description } \\
\hline$U_{I}$ & $4969 \mathrm{psi}$ & Interlaminar shear strength in model I fracture mode \\
$U_{I I}, U_{I I I}$ & $8805 \mathrm{psi}$ & Interlaminar shear strength in mode II and mode III fracture mode \\
$K_{I}$ & $3.4 \mathrm{E}+9$ & Laminate -1 \\
$K_{I I}, K_{I I I}$ & $1.2 \mathrm{E}+9$ & Laminate -1 \\
$K_{I}$ & $2.5 \mathrm{E}+9$ & Laminate -2 \\
$K_{I I}, K_{I I I}$ & $8.8 \mathrm{E}+8$ & Laminate -2 \\
\hline \hline
\end{tabular}




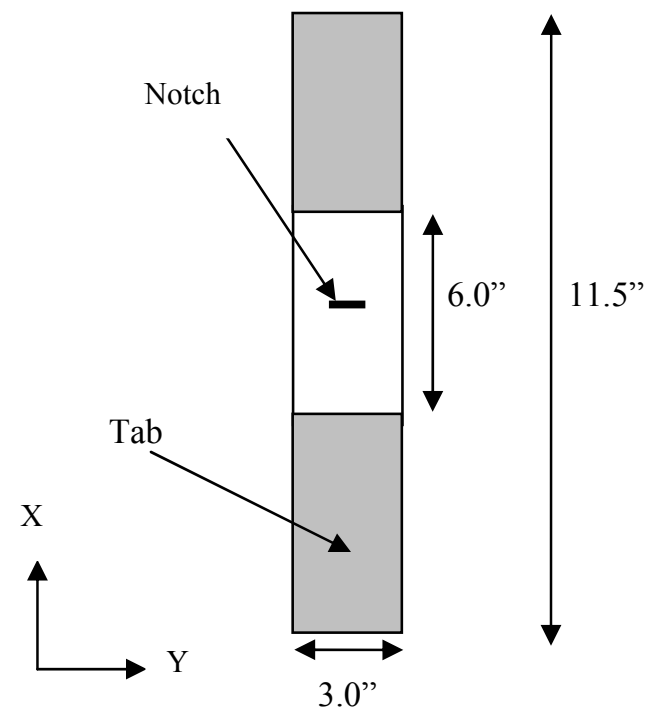

Figure 1. Center-notched Tensile Specimen.

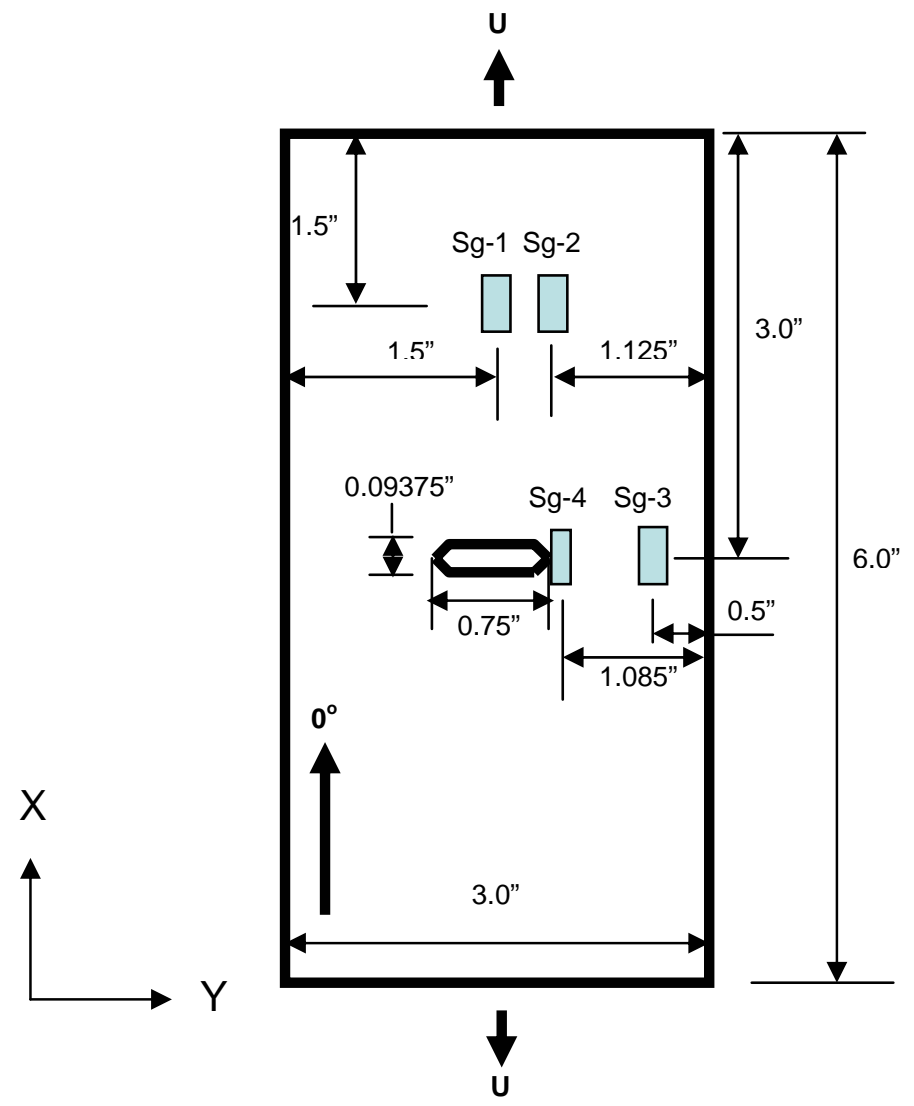

Figure 2. Strain gauge locations on the specimen. 


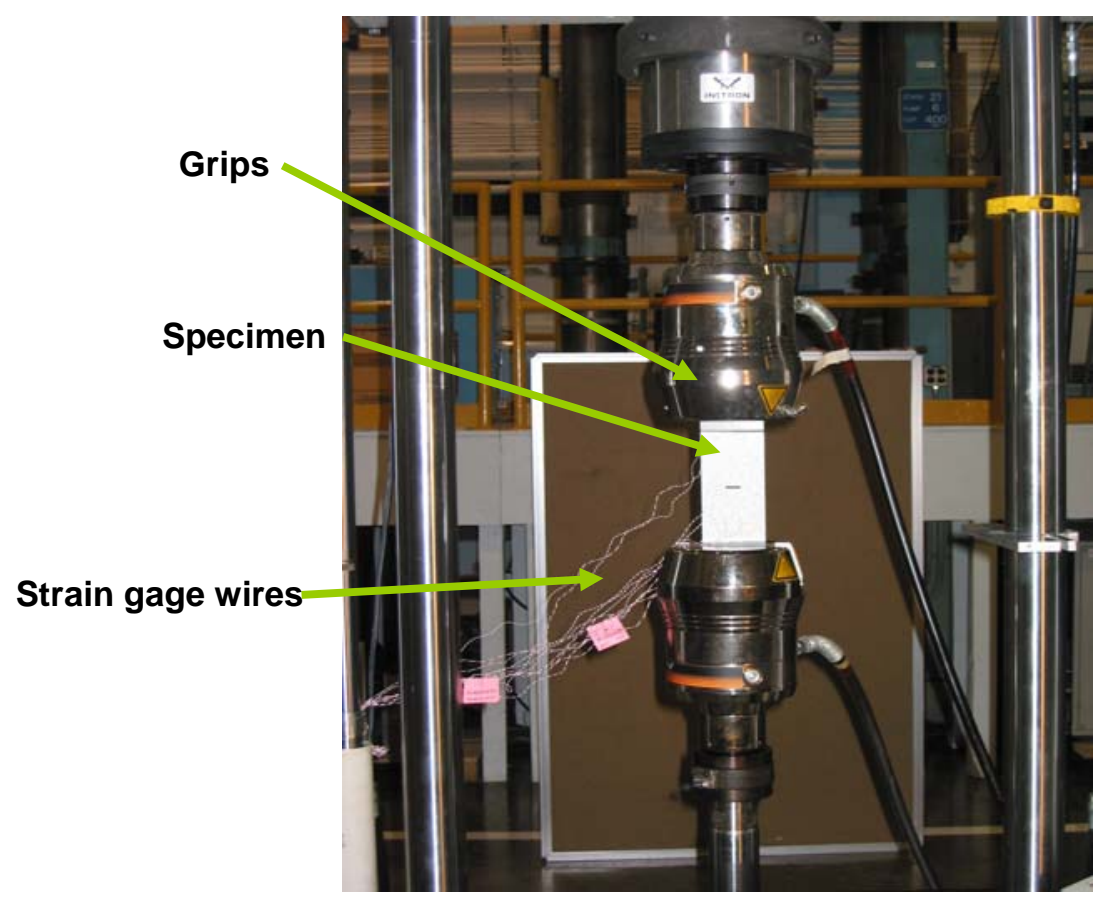

Figure 3. Test Setup.

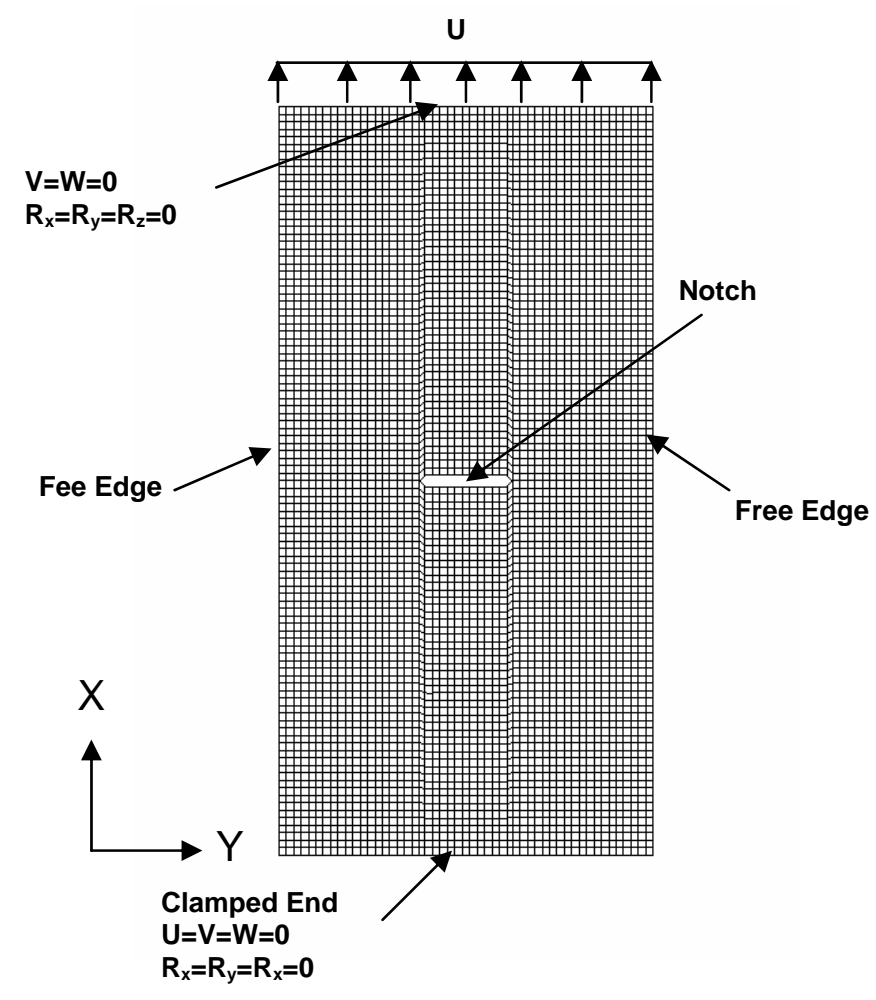

Figure 4. Finite-Element Mesh. 


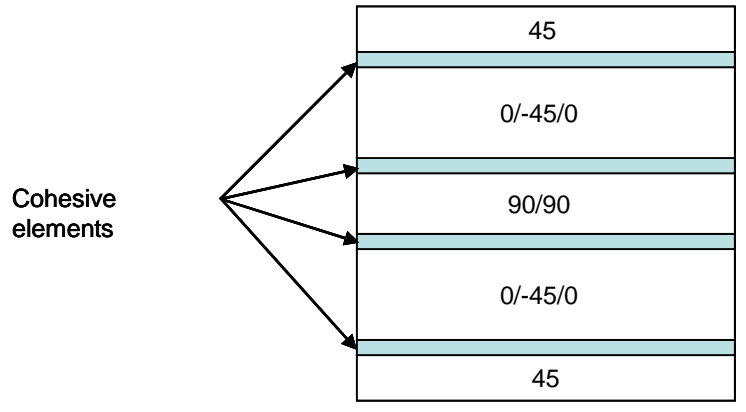

Laminate - 1

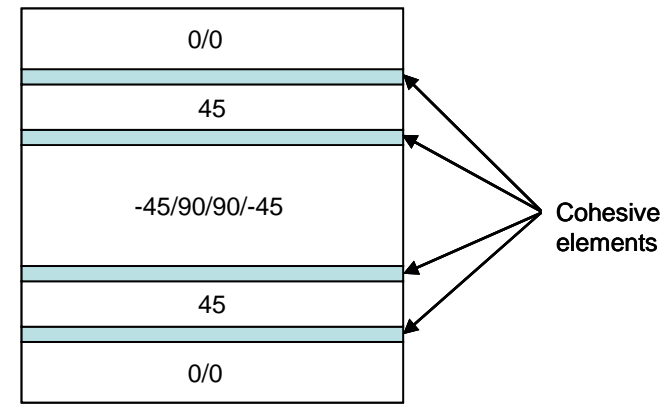

Laminate - 2

Figure 5. Laminates showing the location of cohesive layers.

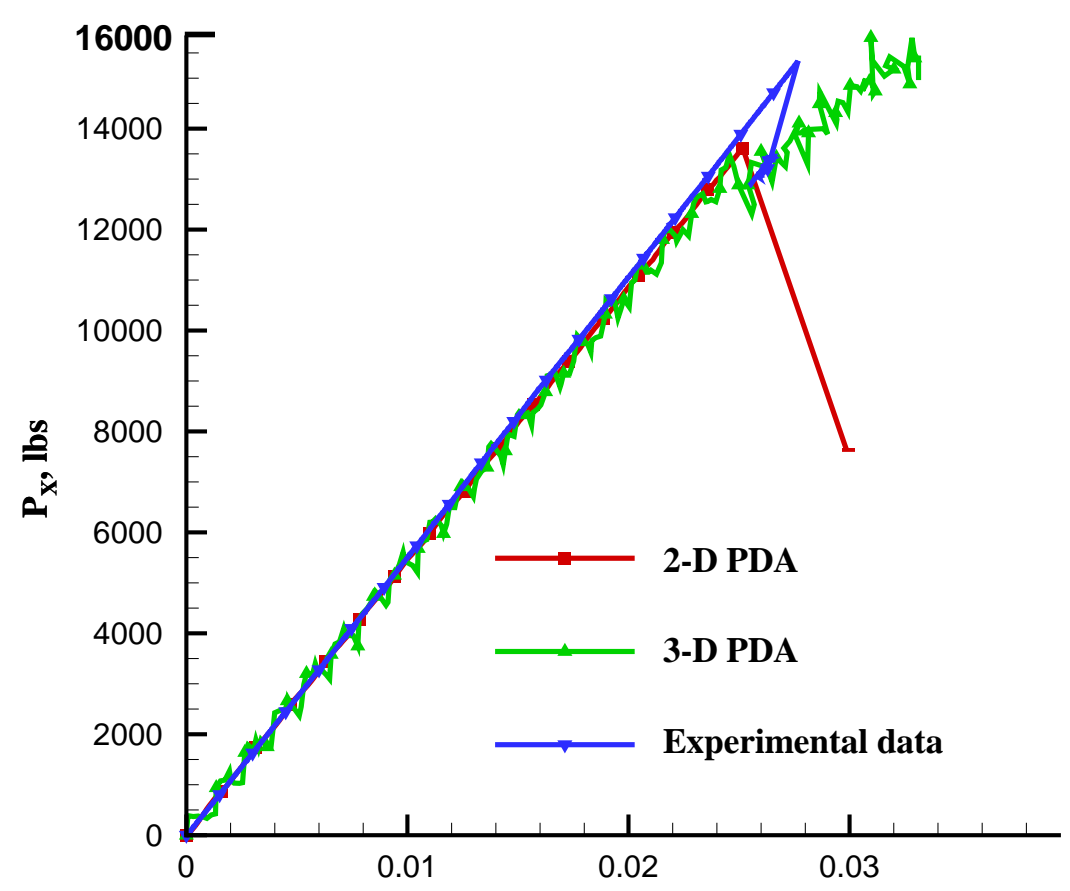

Displacement, $\Delta_{x}$, of a 4-in. long section, inches

Figure 6. Load vs. End-Displacement of Laminate-1. 


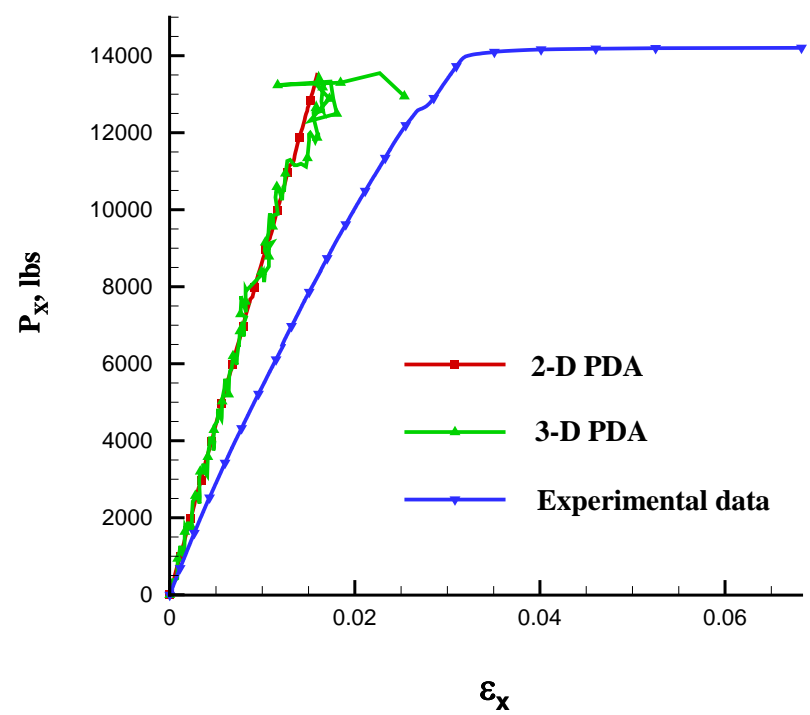

Figure 7. Load vs. strain in Laminate-1.

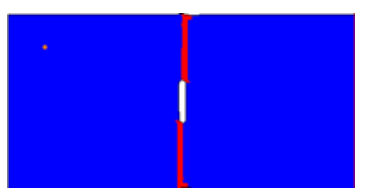

0 Degree ply Fiber Failure

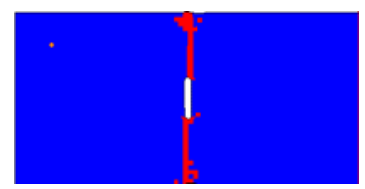

45 Degree ply Fiber Failure

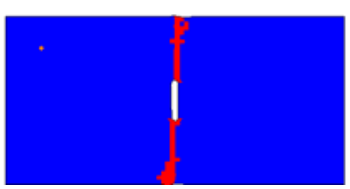

-45 Degree ply Fiber Failure

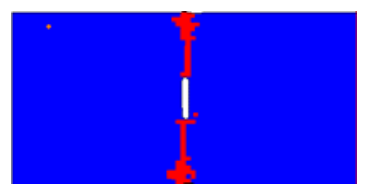

90 Degree ply Matrix Failure

Figure 8. Intralaminar damages obtained from 2-D PDA of Laminate-1 at $P_{X}=13613.0$ lbs.

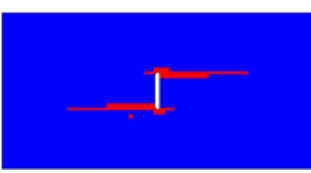

0 Degree ply Matrix Failure

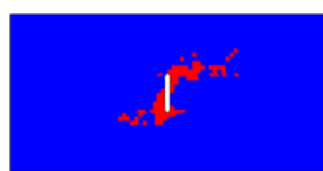

45 Degree ply Matrix Failure

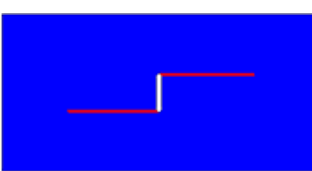

-45 Degree ply Fiber Failure

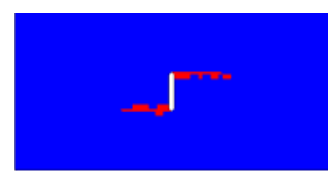

90 Degree ply Matrix Failure

Figure 9. Intralaminar damages obtained from 3-D PDA of Laminate-1 at $\mathbf{P}_{X}=15316.0$ lbs.

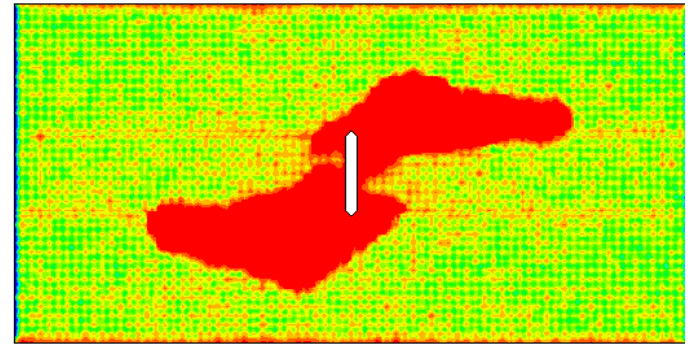

a) $45 / 0$ Interface

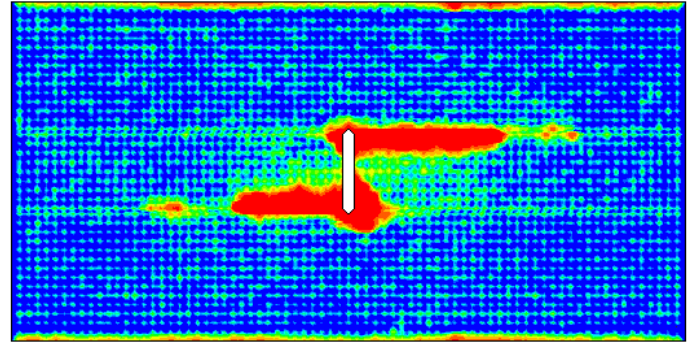

b) $0 / 90$ Interface

Figure 10. Delamination predictions for laminate-1 at $\mathbf{P}_{X}=15316.0 \mathrm{lbs}$. 


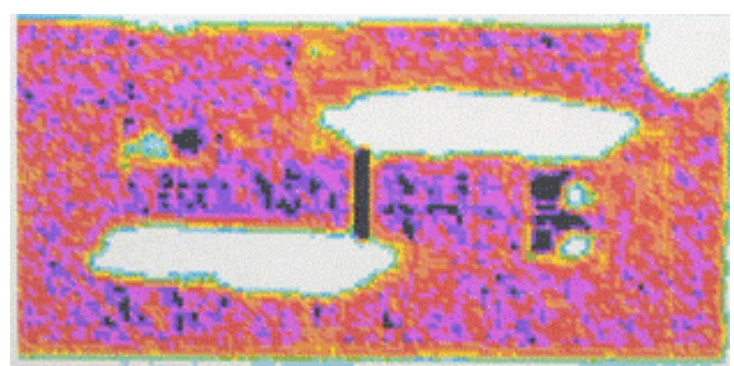

a) C-Scan

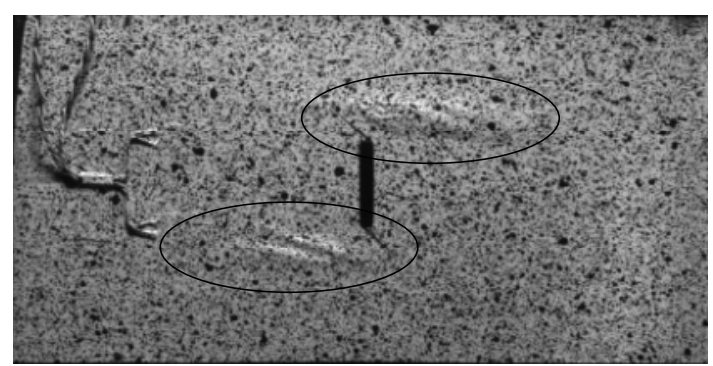

b) Picture Showing popping of $45^{\circ}$ ply

Figure 11. C-Scan picture showing delamination and a digital photo showing debond in laminate-1 at $P_{X}=15300.0$ lbs.

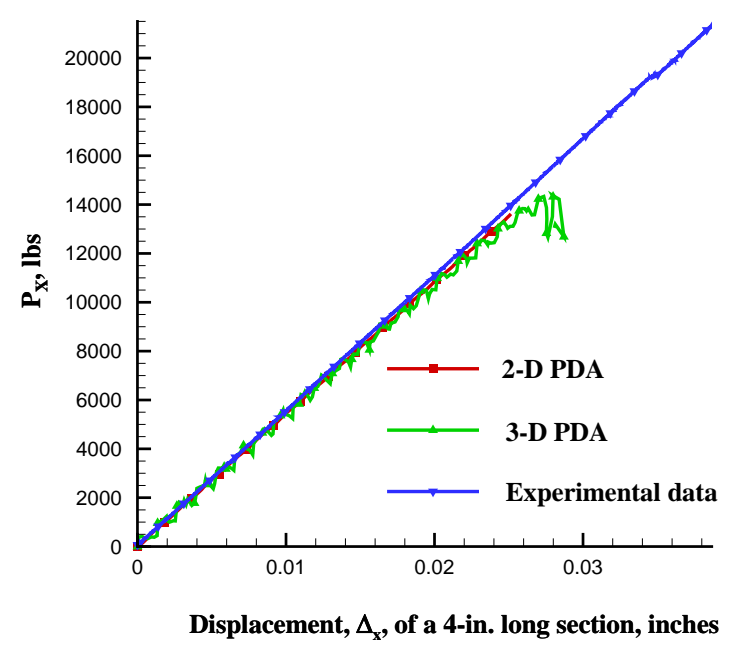

Figure 12. Load vs. End-displacement of Laminate-2.

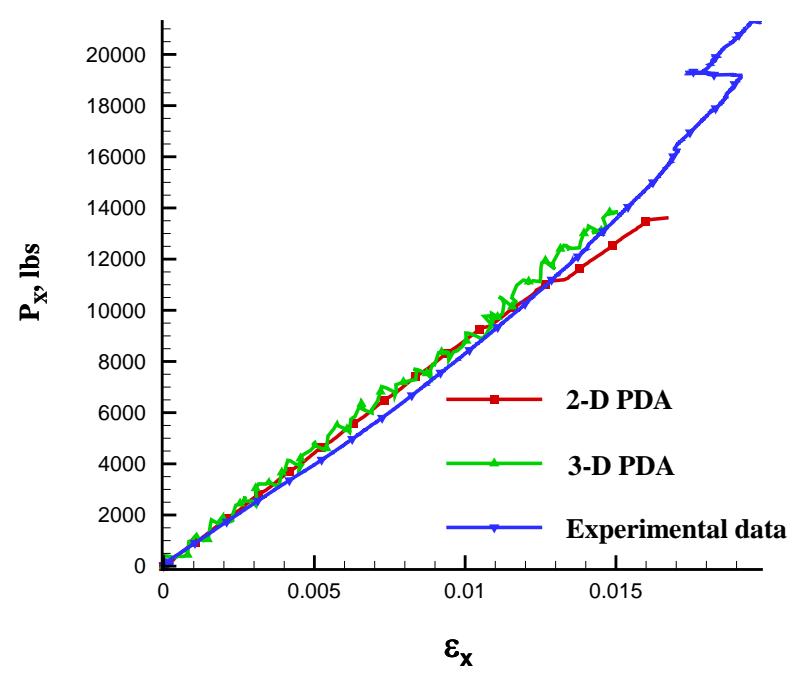

Figure 13. Load vs. strain in Laminate-2. 


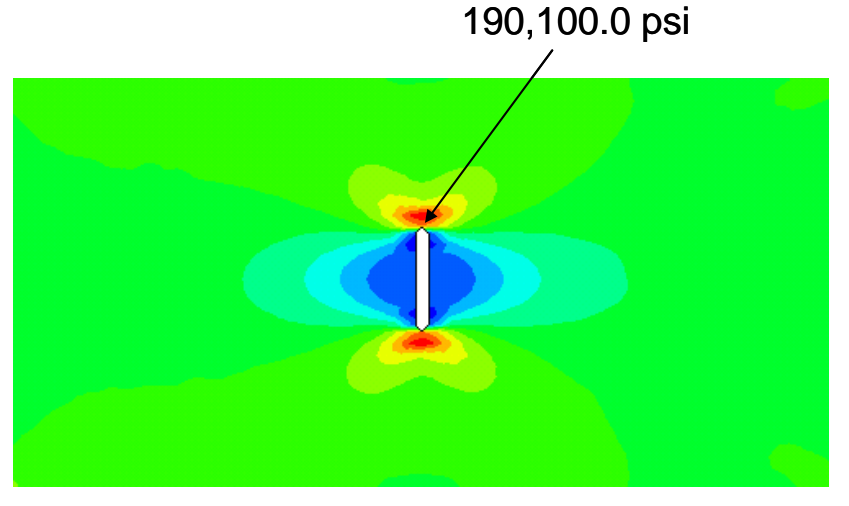

a) $\mathbf{P}_{\mathrm{X}}=8,371.0 \mathrm{lbs}$

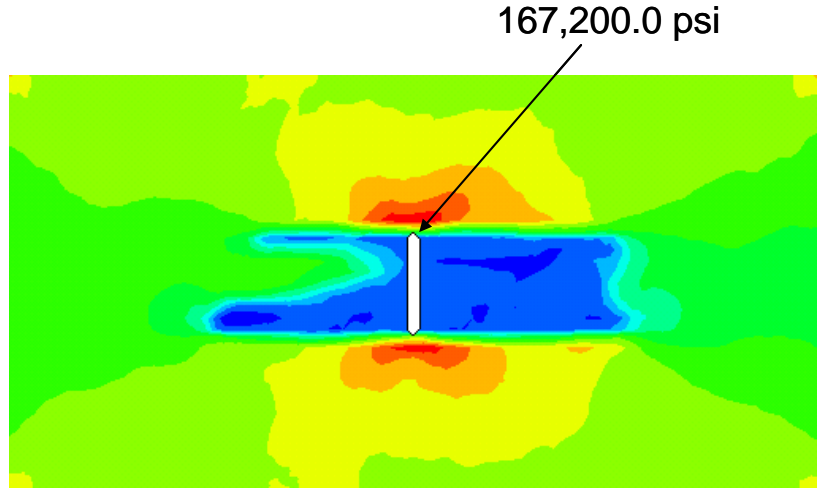

b) $P_{X}=13,411.0 \mathrm{lbs}$

Figure 14. Axial Stress distribution in $0^{\circ}$ ply of Laminate-2 before and after delamination at 0/45 interface.

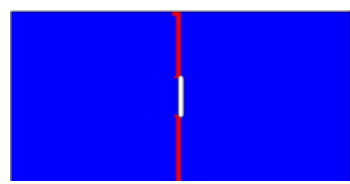

0 Degree ply Fiber Failure

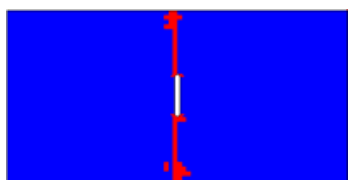

45 Degree ply Fiber Failure

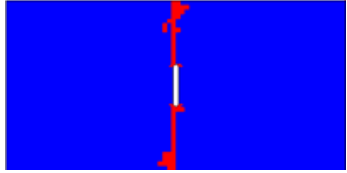

-45 Degree ply Fiber Failure

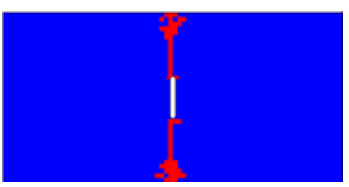

90 Degree ply Matrix Failure

Figure 14. Intralaminar damages obtained from 2-D PDA of Laminate-2 at $P_{X}=13618.0$ lbs.

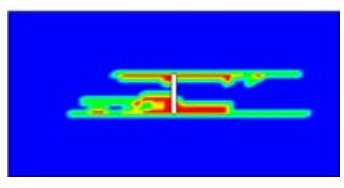

0 Degree ply Matrix Failure

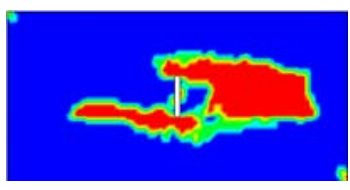

45 Degree ply Matrix Failure

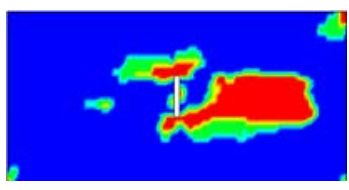

-45 Degree ply Matrix Failure

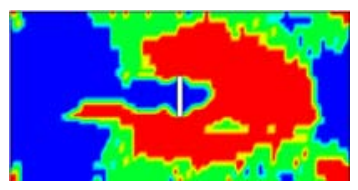

90 Degree ply Matrix Failure

Figure 15. Intralaminar damages obtained from 3-D PDA of Laminate-2 at $P_{X}=14387.0 \mathrm{lbs}$. 


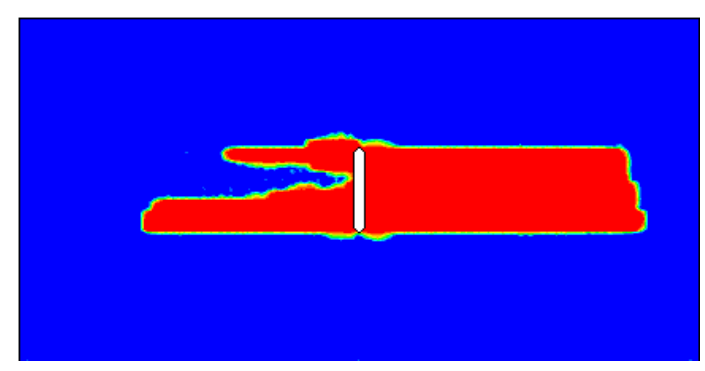

a) $0 / 45$ Interface

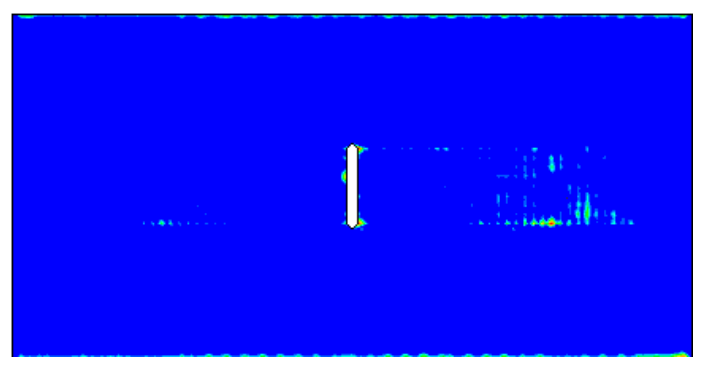

b) $45 /-45$ Interface

Figure 16. Delamination predictions for laminate-2 at $P x=14387.0 \mathrm{lbs}$.

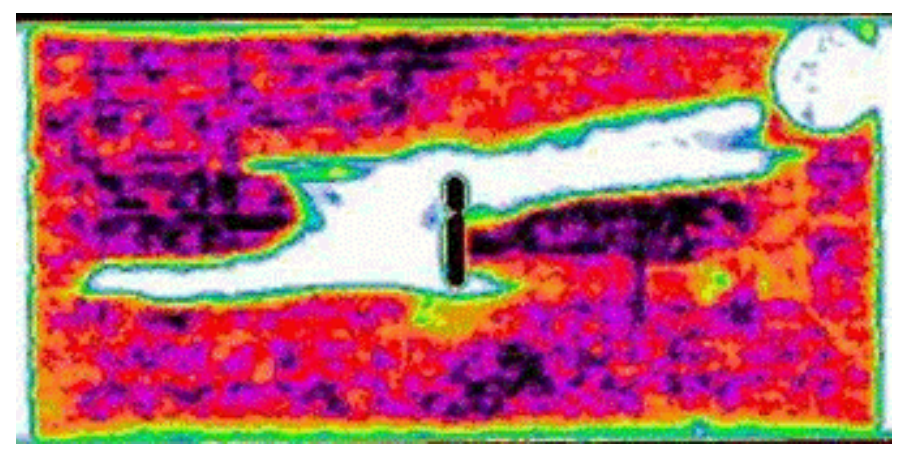

Figure 17. C-Scan picture of the damage in specimen of Laminate-2 at $P_{X}=21280.0$ lbs. 